\title{
Hemodiyaliz Hastalarında Kaşıntının Varlığı ile Uyku ve Anksiyete Arasındaki İlişkinin İncelenmesi
}

\author{
Investigation of the Relationship Between Pruritus and Sleep \\ and Anxiety in Hemodialysis Patients
}

\author{
İlknur ÖZKAN ${ }^{1}$, Seçil TAYLAN ${ }^{2}$
}

${ }^{I}$ Dr. Öğr. Üyesi, Akdeniz Üniversitesi, Kumluca Sağllk Bilimleri Fakültesi, Hemşirelik Bölümü, İç Hastalıkları Hemşireliği AD, Antalya, Türkiye

${ }^{2}$ Dr. Öğr. Üyesi, Akdeniz Üniversitesi, Kumluca Sağllk Bilimleri Fakültesi, Hemşirelik Bölümü, Cerrahi Hastalkklar Hemşireliği AD, Antalya, Türkiye

Geliş Tarihi: 26 Nisan2020

Kabul Tarihi: 20 Mayis 2020

\section{İletişim / Correspondence:}

İlknur ÖZKAN

E-posta: ilknurozkan@akdeniz.edu.tr

\section{Özet}

Amaç: $\mathrm{Bu}$ çalışmanın amacı hemodiyaliz hastalarının yaşadığı kaşıntıyı çok boyutlu değerlendirmek ve kaşıntının, uyku ile anksiyete arasındaki ilişkisini incelemektir.

Gereç ve Yöntem: Tanımlayıcı nitelikte olan bu çalışma, Ocak- Mart 2020 tarihleri arasında Akdeniz bölgesinde iki devlet hastanesinin diyaliz merkezinde gerçekleştirildi. Çalışmaya hemodiyaliz tedavisi alan 114 hasta dahil edildi. Çalışmanın verileri, Tanıtıcı Bilgi Formu, 5 D Kaşıntı ölçeği, Richard-Campbell Uyku Ölçeği, Spielberg Durumluk-Sürekli Kaygı Ölçeği kullanılarak elde edildi.

Bulgular: Çalışmada hastaların yarısına yakınının ciddi ve orta derecede kaşıntı yaşadığ belirlendi. Hastaların 5 D kaşıntı ölçeğinden toplam $12.44 \pm 7.11$ (orta şiddette); sürekli kayg1 ölçeğinden toplam 49.54 $\pm 13,03$; Richard-Campbell Uyku Ölçeğinden toplam $50.44 \pm 27.71$ puan aldıkları saptandı. Hastaların \% 41.2'sinin çok kötü uyku kalitesine sahip olduğu belirlendi. Kaşıntı ve uyku arasında orta derecede $(\mathrm{p}=.000 ; \mathrm{r}=-.679)$; kaşıntı ve anksiyete arasında yüksek derede $(\mathrm{p}=.000$; $\mathrm{r}=.706$ ) korelasyonel bir ilişki bulundu. Yapılan lineer regresyonda kaşıntı hem anksiyetenin hem de uykunun belirleyicisi olarak saptand.

Sonuç: Bu çalışmada hemodiyaliz hastalarının yarısına yakınının orta ve şiddetli derecede kaşıntı yaşadığı ve günlük yaşamlarının önemli derecede etkilendiği belirlendi. Çalışmanın diğer önemli bir sonucu da kaşıntı ile uyku kalitesi ve anksiyete arasındaki ilişkinin varlığıdır. Bu sonuçlara dayanarak hemodiyaliz hastalarında etkin semptom yönetiminin sağlanması için kaşıntı semptomlarının diyaliz hemşireleri tarafından çok boyutlu değerlendirilmesi önerilmektedir. Kaşıntı semptomlarının hemodiyaliz hastalarında çok boyutlu değerlendirilmesi ile uyku, anksiyete ve yaşam kalitesi üzerindeki etkisinin belirlenmesini sağlayarak hastaların morbiditesini azaltacağı ve yaşam kalitesini artıracağı öngörülmektedir.

Anahtar kelimeler: Hemodiyaliz; Kaşıntı; Anksiyete; Uyku Kalitesi.

\section{Abstract}

Objective: The aim of this study is to evaluate the itching experienced by hemodialysis patients in multiple dimensions and to examine the relationship between itching and sleep and anxiety. 
Method: This descriptive study was conducted in the dialysis center of two state hospitals in the Mediterranean region between January-March 2020. 114 patients who underwent hemodialysis session were included in the study. The data of the study were obtained by using the Introductory Information Form, 5 D Itch scale, Richard-Campbell Sleep Scale (R-CUS), Spielberg State-Trait Anxiety Scale.

Results: In the study, it was determined that almost half of the patients experienced severe and moderate itching. The total mean score of the patients on the 5D itch scale was $12.44 \pm 7.11$ (moderate); $49.54 \pm 13.03$ from the trait anxiety scale; It was determined that they got $50.44 \pm 27.71$ points from the Richard-Campbell Sleep Scale. It was determined that $41.2 \%$ of the patients had very bad sleep. Moderate between itching and sleep $(\mathrm{p}=.000 ; \mathrm{r}=-.679)$; Correlation was found between itching and anxiety at high level $(p=.000 ; r=-$. 706). In the linear regression, itching was determined as a determinant of both anxiety and sleep.

Conclusion: In this study, it was determined that almost half of hemodialysis patients experienced moderate and severe itching and their daily lives were significantly affected. Another important result of the study was the relationship between itching and sleep quality and anxiety. Based on these results, it is recommended that the itching symptoms are evaluated multi-dimensionally by the dialysis nurses to ensure effective symptom management in hemodialysis patients. Multidimensional evaluation of itching symptoms in hemodialysis patients is thought to decrease the morbidity and increase the quality of life by enabling the determination of the effect on sleep, anxiety and quality of life.

Keywords: Hemodialysis; Itching; Anxiety; Sleep Quality.

\section{GİRIŞ}

Kaşınt1, Kronik Böbrek Yetmezliğinde (KBY) yaygın görülen ve rahatsız edici bir semptomdur (1). Genellikle kaşıntı, diyalizin başlamasından kısa bir süre önce veya diyaliz sonrası herhangi bir zamanda görülebilmekte ve kaşıntıyı açıklayabilecek başka herhangi bir aktif hastalığın kanıtı olmadan ortaya çıkabilmektedir. Hemodiyaliz (HD) hastalarında kaşıntı prevalansı \%2284 arasında değişmektedir. Kaşıntı, hemodiyaliz uygulanan hastalarda, periton diyalizi uygulananlara göre daha yaygındır (2-4). Üremik kaşıntı, epizodik, sabit veya lokalize olabilmekte ve yoğunluğu hafif ile şiddetli düzey arasında değişebilmektedir (5). En sık etkilenen bölgeler baş, sirt, uzuvlar ve gögüs olmakla birlikte hemodiyaliz hastalarının yarısından fazlası genel kaşıntı bildirmektedir $(1,2)$.

Üremik kaşıntının altında yatan mekanizma iyi anlaşılmamıştır; mevcut teoriler arasında sekonder hiperparatiroidizm, iki değerlikli iyon anormallikleri, histamin, alerjik duyarlılaşma, cilt mast hücrelerinin çoğalması, demir eksikliği anemisi, hipervitaminoz A, kseroz, nöropati ve nörolojik değişiklikler, opioid sistem tutulumu ( $\kappa$ reseptörlerinin az uyarılması veya $\mu$ reseptörlerinin aşırı ekspresyonu), sitokinler, serum safra asitleri, nitrik oksit veya bunların bir kombinasyonu bulunmaktadır $(2,6)$.

Hemodiyaliz hastalarında kaşıntı, derideki lezyonlar, kanama, kronik yorgunluk ve uyku bozuklukları gibi fizyolojik sorunlara ve öfke, anksiyete-depresyon ve sosyal izolasyon gibi psikolojik sorunlara yol açabilir. Bu sorunlar hastaların yaşam kalitesini azaltarak, kişisel bakım yeteneğini azaltır ve hastalığa uyumu güçleştirir (7-9). Üremik kaşıntı geceleri daha sık görüldüğünden dolayı hastanın uykusunu ve ruh halini etkilemektedir (10). Çalışmalar, hemodiyaliz hastalarının \%11-26'sının uyku kalitesinin üremik kaşıntıdan dolayı etkilendiğini göstermektedir $(4,8$, 11). Kaşıntı sadece bozulmuş yaşam kalitesi ile ilişkili değil aynı zamanda yüksek psikolojik yük ile de ilişkilidir (12). Kaşıntı sonucunda hastalarda kaşıntı bölgesinde oluşan yaralar rahatsızlık yaratarak benlik saygisında azalmaya neden olabilmektedir $(13,14)$. Kaşıntının şiddeti ve psikososyal etkisi arasında güçlü bir korelasyon 
olduğu, hastalarda anksiyete, depresyon, intihar ve ölüm isteğinin arttığ bildirilmektedir (15). Buna rağmen, sadece birkaç çalışma üremik kaşıntı ile depresyon ve anksiyete arasındaki ilişkiyi araştırmıştır (16-18).

Hemodiyaliz hemşirelerinin, hemodiyaliz hastalarının yaşadığı semptomları tanıması, yönetmesi, yaşam kalitesi üzerindeki etkisinin farkında olmas1 ve biyopsikososyal yaklaşım kullanarak semptomları değerlendirmesi önemlidir. Çalı̧̧malar, hemşirelerin hemodiyaliz hastalarının cilt sorunlarını yönetebilmeleri için bakım ve eğitim yaparak hastaların morbiditelerini azaltıp yaşam kalitelerini artırabileceğine dikkat çekmektedir $(19,20)$. Yine az sayıda çalışma, hemşirelerin uyguladıkları nonfarmakolojik yöntemlerin (masaj, aromaterapi, akuprses, soğuk uygulama, müzik terapi) hemodiyaliz hastalarının yaşadıkları kaşıntıyı azaltıp, yaşam kalitesini, uyku kalitesini, konforlarını arttırdığını göstermiştir $(9,10,21$, 22).

Üremik kaşıntının hemodiyaliz hastaları üzerindeki birçok olumsuz etkisi ve altta yatan fizyopatolojik mekanizmanın tam olarak bilinmemesinden kaynaklı zorluklar nedeniyle, hemodiyaliz uygulanan hastalar arasında kaşıntıyı değerlendirmek zorunlu görünmektedir. Bu çalışma: (1) hemodiyaliz hastalarının yaşadığı kaşıntıyı çok boyutlu değerlendirmek ve (2) hemodiyaliz hastalarında yaşanan kaşıntı ile uyku ve anksiyete arasındaki ilişkiyi incelemek üzere iki ana amaç için gerçekleştirildi. Çalışma sonuçlarının, klinik ortamlarda sıklıkla gözden kaçan bir faktör olan kaşıntının yönetimini sağlamak için uygun ve zamanında önlemlerin planlanabilmesini sağlamada yararlı olacağı öngörülmektedir.

\section{GEREÇ VE YÖNTEM}

\subsection{Araştırmanın tipi ve yeri}

Tanımlayıcı nitelikte olan bu çalışma Akdeniz bölgesinde iki devlet hastanesinin diyaliz merkezinde gerçekleştirildi.

\subsection{Araștırmanın evreni ve örneklemi}

Araştırmanın evrenini iki devlet hastanesinin diyaliz merkezinde hemodiyaliz tedavisi alan hastalar oluşturdu $(\mathrm{N}=122)$. Evreni belli olan örneklem hesaplama yöntemi kullanılarak \%95 güven aralığında örneklem sayısı 93 hasta olarak belirlendi. Araştırmaya, 18 yaş ve üzeri, en az altı aydır HD tedavisi gören, çalışmaya katılmayı kabul eden ve herhangi bir iletişim sorunu olmayan 114 hasta dahil edildi. Kaşıntı için farmakolojik tedavi gören, karaciğer hastalığı (örn. hepatit, siroz) ve öncesinde alerji öyküsü olan hastalar çalışmaya alınmadı.

\subsection{Veri toplama Araçları}

Araştırmanın verileri, Tanıtıcı Bilgi Formu, diyaliz yeterliliği için $\mathrm{Kt} / \mathrm{V}$ ve URR değerleri, $5 \mathrm{D}$ Kaşıntı Ölçeği, Richard-Campbell Uyku Ölçeği (R-CUÖ), Spielberg Durumluk-Sürekli Kayg1 Ölçeği kullanılarak elde edildi.

\subsubsection{Tanıtıcı Bilgi Formu}

$\mathrm{Bu}$ form, literatür $(18,21,23)$ incelenerek araştırmacılar tarafından hazırlandı. Hasta tanıtıcı bilgi formu; hemodiyaliz hastalarınının sosyodemografik özellikleri (yaş, cinsiyet, medeni durum, sosyal güvence, yaşanılan yer, sigara ve alkol kullanımı, vb.) ve hastalık özgeçmişleri ( ilk hastalık tanısı, ek hastalık varlığ diyaliz sayıs1, hemodiyaliz y1l, hemodiyaliz esnasında en sık karşıllaşılan sorunlar, Kt/V, URR değerleri, diyete uyum, cilt kuruluğu, vb.) ile ilgili toplam 21 sorudan oluşmaktadır.

\subsubsection{Diyaliz Yeterliliği}

Diyaliz yeterliliğini değerlendirmek için Kt/V (K: diyalizerin üre klirensi; $\mathrm{t}$ : diyalizin süresi; $\mathrm{V}$ : üre dağılım volümü) ve URR (Üre azalma oranı) değeri kullanıldı. Kt/V değeri Daugirdas formülü kullanılarak hesaplandı (24). URR değeri için $\% 65-70, \mathrm{Kt} / \mathrm{V}$ için ise $>1.2$ diyaliz yeterliliğini göstermektedir.

$\mathrm{Kt} / \mathrm{V}=-\log ($ Upost/Upre-0,008t ) $)+(4-3,5 \mathrm{Upost} /$ Upre) x (Wpre-Wpost) / Wpost

Upost $=$ HD sonrası üre

Upre $=$ HD öncesi üre

Wpost $=$ HD sonrası ağılık

Wpre $=$ HD öncesi ağırlık

$\mathrm{t}=$ HD süresi 
Üre Azalma Oranı (URR):

$\mathrm{URR}=($ Upre-Upost/Upre $) \times 100$

\subsubsection{D Kaşıntı Ölçeği}

5-D Kaşıntı Ölçeği, Elman ve ark. tarafından 2010 yılında geliştirilmiştir. Ölçek, son iki hafta içinde yaşanan kaşıntının süresini, derecesini, seyrini, dağılımını ve kaşıntını yarattığı özürlülüğü değerlendirmektedir. Ölçeğin toplam puan1, minimum 5 puan (kaşıntı yok) ile maksimum 25 puan (maksimum şiddet) arasında değişmektedir. Kaşıntının süresi, derecesi, yönü ve özürlülügü 1 ile 5 puan arasında puanlanmaktadır. Özürlülük boyutu puan1, dört alt bölümün toplam puanının (uyku, sosyal / boş zaman, ev işleri / ayak işleri, iş / okul) ortalamasından elde edilmektedir. Dağglım skoru, etkilenen vücut bölümlerinin sayısına göre 16 vücut bölgesi incelenerek maksimum 5 puan, 0-2: 1 puan, 3-5: 2 puan, 6-10: 3 puan, 11-13: 4 puan ve 14-16: 5 puan ile elde edilmiştir. Ölçeğin Türkçe geçerlilik ve güvenilirlik çalışması Altınok Ersoy ve Akyar tarafindan yapılmıştır. Uyarlama çalışmasında Cronbach Alfa katsayısı 0.608 bulunmuştur (25). Bu çalışmada Cronbach Alfa katsayısı 0.72 olarak belirlendi.

\subsubsection{Richard-Campbell Uyku Ölçeği (R-CUÖ)}

Richards tarafından 1987 yılında geliştirilen RCUÖ, gece uykusunun derinliğini, uykuya dalma süresini, uyanma sıklığını, uyandığında uyanık kalma süresini, uykunun kalitesini ve ortamdaki gürültü düzeyini değerlendiren 6 maddeden oluşan bir ölçektir. Ölçeğin her bir maddesi görsel analog skala yöntemi ile 0 ile 100 arasında yer alan çizelge üzerinde değerlendirilmektedir. Ölçekten alınan " $0-25$ " arası puan çok kötü uykuyu, "76-100" arası puan çok iyi uykuyu belirtmektedir. Ölçek toplam puanı 5 madde üzerinden değerlendirilmekte, ortamdaki gürültü düzeyini değerlendiren 6. madde toplam puan değerlendirmesi dışında bırakılmaktadır. Ölçeğin puanı arttıkça hastaların uyku kaliteleri de artmaktadır. Ölçeğin Türkçeye uyarlama çalışması Özlü ve Özer tarafından 2015 yılında yapılmıştır (26). Cronbach Alfa katsayısı ölçeğin uyarlama çalışmasında $0,91(26)$, bu çalışmada 0.84 olarak bulundu.

\subsubsection{Spielberg Durumluk-Sürekli Kaygı Ölçeği (State- Trait Anxiety Inventory $=$ STAI)}

Ölçek, Spielberger ve arkadaşları tarafindan 1970 yıllında geliştirilmiş, Türk toplumuna uyarlaması Öner ve Le Compte tarafından yapılmış, durumluk ve sürekli kaygı düzeylerini 20 soru ile ayrı ayrı ölçen Likert tipi bir ölçektir (27). Ölçek dörtlü likert yapıdadır ve her iki ölçekten elde edilen toplam puan değeri 20-80 arasında değişmektedir. Yüksek puanlar yüksek kaygı seviyelerini, düşük puanlar düşük kayg1 seviyelerini göstermektedir.

Durumluk-Sürekli Kaygı Ölçeği'nde iki tür ifade bulunmaktadır. Doğrudan ifadeler olumsuz duyguları, tersine dönmüş ifadeler ise olumlu duyguları göstermektedir. Bu çalışmada sadece sürekli kayg1 ölçeği alt boyutu kullanılmıştır. Sürekli Kayg1 Ölçeğindeki tersine dönmüş ifadeler 26, 27,30, 33, 36 ve 39'uncu maddeleri oluşturur. Doğrudan ve tersine dönmüş ifadelerin ayrı ayrı toplam ağırlıkları bulunduktan sonra doğrudan ifadeler için elde edilen toplam ağırlık puanından, ters ifadelerin toplam ağırlık puanı çıkarılır. Bu sayıya, önceden saptanmış ve değişmeyen bir değer eklenir. Sürekli Kayg1 Ölçeği için bu değer 35'tir. En son elde edilen değer bireyin kayg1 puanıdır. Sürekli Kayg1 Ölçeği (SKÖ), kişinin genelde, yaşama eğilimi gösterdiği kaygının sürekliliğini ölçmeyi amaçlamaktadır (27).

\subsection{Verilerin Toplanması}

Veriler, araştırmacılar tarafindan hastalar hemodiyaliz tedavisi aldığı sırada gerekli açıklamalar yapıldıktan sonra yüz yüze görüşme yöntemi ile toplandi. Formların doldurulması yaklaşı 15-20 dakika sürdü.

\subsection{Araştırma Etiği}

Araştırmaya başlamadan önce Akdeniz Üniversitesi Klinik Araştırmalar Etik Kurulu'ndan (Karar no:KAEK-36) onay ve hastalardan aydınlatılmış onam alındı. 


\subsection{Verilerin Analizi}

Çalışmada elde edilen bulguların istatistiksel analizleri için SPSS 21.0 İstatistik paket programı kullanıldı. Çalışma verileri, frekans, yüzde, ortalama, standart sapma gibi tanımlayıcı istatistiksel metotlar ile değerlendirildi. 5 D kaşıntı ölçeğinin diğer ölçeklerle ilişkisinin yönünü belirlemek için Pearson korelasyon testi ve hemodiyaliz hastalarında uyku ve anksiyetinin yordayıcılarının ilişkisinin derecesini değerlendirmek için Lineer regression analizi yapıldı. Sonuçlar \%95 güven aralığında ve $\mathrm{p}<0.05$ anlamlılık düzeyinde değerlendirildi.

\section{BULGULAR}

Hemodiyaliz tedavisi alan hastaların yaş ortalamasının 59.26 \pm 14.07 olduğu ve \%29.8'inin 5564 yaşlarında, \%62.3'ünün erkek, \%64.9'unun ilköğretim mezunu, \%73.7'sinin evli, \%92.1'sinin çalışmadığı, \% 70.2'sinin ilçede yaşadığ 1 , $\% 89.5$ 'inin sosyal güvencesi olduğu belirlendi. Hastaların hastalık öncesi \%44.7'sinin sigara, \%21.1'inin alkol kullandığ 1 , hastalık sonrası \%11.4'ünün sigara, \%5.3'ünün alkol kullanmayı sürdürüdüğü saptandı (Tablo 1).

Hastaların \%33.3'ünde diyabet nedeni ile böbrek yetmezliği geliştiği, \%63.2'sinin en az bir ek hastalığının olduğu, \%54.4'ünün diyetine uyduğu, \%67'sinin diyaliz ile ilgili eğitim aldığ 1 , \%87.8'inin haftada $3 \mathrm{kez}$ diyalize girdiği ve $\% 51.8$ 'inin 5 yıldan daha az süredir $(5.70 \pm 4.88)$ diyaliz tedavisi aldığı saptandı. Hastaların $\mathrm{Kt} / \mathrm{V}$ değer ortalamasının $1.53 \quad \pm .33$ olduğu ve \%34.2'sinin 1.2-1.4 değer aralı̆̆ında yer aldığ1; URR değer ortalamasının $70.32 \pm 7.20$ olduğu ve \%83.3'ünün \%65 üzerinde değere sahip olduğu, \%57'sinin cilt kuruluğu sorunu yaşadığ 1 belirlendi (Tablo 2).

Hastaların, 5-D KÖ'nün alt boyutlarından aldıkları puan ortalamaları kaşıntının süresi için $2.38 \pm 1.40$, kaşıntının şiddeti için $2.42 \pm 1.35$, kaşıntının seyri için $2.33 \pm 1.37$, kaşıntının günlük yaşam aktivitelerine etkisi için 2.66 \pm 1.42 , kaşıntının vücuttaki dağılımı için $2.63 \pm 1.44$ ve ölçeğin genel toplam puan1 $12.44 \pm 7.15$ olarak bulundu. Hastalar, SKÖ' den toplam 49.54 \pm 13.03 ve R-CUÖ'den toplam $50.44 \pm 27.71$ puan aldıkları ve hastaların \% 41.2'sinin çok kötü uyku kalitesine sahip olduğu belirlendi (Tablo 3).

Hastaların \%44.7'sinin kaşıntısının altı saatten az sürdüğü, \%34.2'sinin ciddi derecede kaşıntı yaşadığı, \%36'sının kaşıntısında biraz iyileşme olduğunu ancak hala devam ettiği, \%21.3'ünün kaşıntısının yaşamını daima etkilediği saptandı (Tablo 4).

SKÖ ve R-CUÖ ile 5D KÖ toplam ve alt boyutlarının korelasyonu incelendiğinde, 5D-KÖ toplam ve alt boyutları ile SKÖ ile pozitif ve yüksek seviyede; R-CUÖ ile negatif ve orta seviyede istatiksel olarak anlamlı ilişki olduğu saptand1 (Tablo 5).

Araştırmada hastaların anksiyete ve uyku düzeylerinin yordamasında tek değişkenli analizlerde istatistiksel olarak anlamlı farklılık saptanan değişkenler ve ölçek puanları Stepwise Multiple Linear Regression analizi ile değerlendirildi. SKÖ puanında en iyi model üçüncü adımda, RCUÖ puanında en iyi model altıncı adımda oluştu (Tablo 6). SKÖ ve R-CUÖ için Durbin-Watson değeri model geçerliliğini sağladı $(D=1.756$, $\mathrm{D}=1.921$ ). Tolerans ve VIF değerleri, değişkenlerin eşitliğinin bulunmadığını gösterdi.

SKÖ standart sapmasını, 5DKÖ Kaşıntının Seyri standart sapmasındaki bir birimlik artışın .476 birim arttırdı $\breve{g}$, R-CUÖ standart sapmasındaki bir birimlik artışın ise .449 birim azalttığ belirlendi. Deride kuruluk varlığında bir birimlik artışın SKÖ puanın .275 birim arttırdığ 1 saptandı (Tablo 6).

R-CUÖ standart sapmasını 5D KÖ (kaşıntının seyri) standart sapmasındaki bir birimlik artışın 228, 5DKÖ (kaşıntının süresi) standart sapmasındaki bir birimlik artışın .440, 5DKÖ (kaşıntının vücutta dağılımı) standart sapmasındaki bir birimlik artışın 1.326, 5DKÖ (kaşıntının günlük yaşam aktivitesine etkisi) standart sapmasındaki bir birimlik artışın 3.143, SKÖ standart sapmasındaki bir birimlik artışın .550 birim azalttığı belirlendi. Deride kuruluk varlığında bir birimlik artışın R-CUÖ puanını 2.944 birim azalttığı saptandı (Tablo 6). 
Tablo 1. Tanıtıcı Özellikler

\begin{tabular}{|c|c|c|c|}
\hline \multicolumn{2}{|l|}{ Tanıtıcı Özellikler } & \multirow{2}{*}{$\begin{array}{c}\mathrm{n}(114) \\
43 \\
71\end{array}$} & \multirow{2}{*}{$\begin{array}{c}\% \\
37.7 \\
62.3 \\
\end{array}$} \\
\hline Cinsiyet & $\begin{array}{l}\text { Kadın } \\
\text { Erkek }\end{array}$ & & \\
\hline $\begin{array}{l}\text { Yaş } \\
\text { Ort. } \pm \text { SS } \\
59.26 \pm 14.07\end{array}$ & $\begin{array}{l}18-44 \\
45-54 \\
55-64 \\
65-74 \\
>75\end{array}$ & $\begin{array}{l}14 \\
24 \\
34 \\
30 \\
12\end{array}$ & $\begin{array}{l}12.3 \\
21.1 \\
29.8 \\
26.3 \\
10.5\end{array}$ \\
\hline Eğitim & $\begin{array}{l}\text { Okur-yazar değil } \\
\text { Okur-yazar } \\
\text { İlköğretim } \\
\text { Ortaöğretim } \\
\text { Üniversite }\end{array}$ & $\begin{array}{c}15 \\
14 \\
74 \\
7 \\
4\end{array}$ & $\begin{array}{c}13.2 \\
12.3 \\
64.9 \\
6.1 \\
3.5 \\
\end{array}$ \\
\hline Medeni Durum & $\begin{array}{l}\text { Evli } \\
\text { Bekâr }\end{array}$ & $\begin{array}{l}84 \\
30 \\
\end{array}$ & $\begin{array}{l}73.7 \\
26.3 \\
\end{array}$ \\
\hline Çalışma durumu & $\begin{array}{l}\text { Çalışıyor } \\
\text { Çalışmıyor }\end{array}$ & $\begin{array}{c}9 \\
105 \\
\end{array}$ & $\begin{array}{c}7.9 \\
92.1\end{array}$ \\
\hline Yaşanılan Yer & $\begin{array}{l}\text { İl } \\
\text { İlçe } \\
\text { Köy }\end{array}$ & $\begin{array}{c}6 \\
80 \\
28\end{array}$ & $\begin{array}{c}5.3 \\
70.2 \\
24.6\end{array}$ \\
\hline Sosyal Güvence & $\begin{array}{l}\text { Var } \\
\text { Yok }\end{array}$ & $\begin{array}{c}102 \\
12 \\
\end{array}$ & $\begin{array}{l}89.5 \\
10.5\end{array}$ \\
\hline $\begin{array}{l}\text { Hastalık öncesi sigara } \\
\text { kullanımı }\end{array}$ & $\begin{array}{l}\text { Evet } \\
\text { Hayır }\end{array}$ & $\begin{array}{l}51 \\
63\end{array}$ & $\begin{array}{l}44.7 \\
55.3\end{array}$ \\
\hline $\begin{array}{l}\text { Hastalık öncesi alkol } \\
\text { kullanımı }\end{array}$ & $\begin{array}{l}\text { Evet } \\
\text { Hayır }\end{array}$ & $\begin{array}{l}24 \\
90\end{array}$ & $\begin{array}{l}21.1 \\
78.9 \\
\end{array}$ \\
\hline Şimdi sigara kullanımı & $\begin{array}{l}\text { Evet } \\
\text { Hayır }\end{array}$ & $\begin{array}{c}13 \\
101\end{array}$ & $\begin{array}{l}11.4 \\
88.6\end{array}$ \\
\hline Şimdi alkol kullanımı & $\begin{array}{l}\text { Evet } \\
\text { Hayır }\end{array}$ & $\begin{array}{c}6 \\
108\end{array}$ & $\begin{array}{c}5.3 \\
94.7\end{array}$ \\
\hline
\end{tabular}


Tablo 2. Hastalık ile ilgili özellikler

\begin{tabular}{|c|c|c|c|}
\hline \multicolumn{2}{|l|}{ Tanıtıcı Özellikler } & \multirow[b]{2}{*}{$\begin{array}{c}\mathrm{n}(114) \\
19 \\
37 \\
3 \\
38 \\
17\end{array}$} & \multirow[b]{2}{*}{$\begin{array}{c}\% \\
16.7 \\
32.5 \\
2.6 \\
33.3 \\
14.9\end{array}$} \\
\hline İlk Tanı & $\begin{array}{l}\text { Kronik Glomerülonefrit } \\
\text { Hipertansif Böbrek Hastalığı } \\
\text { Pyelonefrit } \\
\text { Diyabetik Nefropati } \\
\text { Polikistik Böbrek Hastalığı }\end{array}$ & & \\
\hline Ek Hastalık Varlığı & $\begin{array}{l}\text { Var } \\
\text { Yok }\end{array}$ & $\begin{array}{l}72 \\
42\end{array}$ & $\begin{array}{l}63.2 \\
36.8\end{array}$ \\
\hline Diyete Uyum & $\begin{array}{l}\text { Evet } \\
\text { Hayir }\end{array}$ & $\begin{array}{l}62 \\
52\end{array}$ & $\begin{array}{l}54.4 \\
45.6\end{array}$ \\
\hline Haftalık Hemodiyaliz Sayısı & $\begin{array}{l}2 \text { Seans } \\
3 \text { Seans } \\
4 \text { Seans }\end{array}$ & $\begin{array}{c}4 \\
100 \\
10\end{array}$ & $\begin{array}{c}3.4 \\
87.8 \\
8.8\end{array}$ \\
\hline $\begin{array}{l}\text { Program dışında diyalize } \\
\text { girme }\end{array}$ & $\begin{array}{l}\text { Evet } \\
\text { Hayır }\end{array}$ & $\begin{array}{c}5 \\
109\end{array}$ & $\begin{array}{c}4.4 \\
95.6\end{array}$ \\
\hline $\begin{array}{l}\text { Diyaliz Y1lı } \\
5.70 \pm 4.88\end{array}$ & $\begin{array}{l}<5 \text { years } \\
5-10 \text { years } \\
>10 \text { years }\end{array}$ & $\begin{array}{l}59 \\
36 \\
19\end{array}$ & $\begin{array}{l}51.8 \\
31.6 \\
16.7\end{array}$ \\
\hline $\begin{array}{l}\text { Hemodiyaliz sırasında en } \\
\text { sık karşılaşılan sorunlar }\end{array}$ & $\begin{array}{l}\text { Hipotansiyon } \\
\text { Bulantı-kusma } \\
\text { Kramp } \\
\text { Halsizlik }\end{array}$ & $\begin{array}{l}47 \\
15 \\
35 \\
17\end{array}$ & $\begin{array}{l}41.2 \\
13.2 \\
30.7 \\
15.0\end{array}$ \\
\hline $\begin{array}{l}\mathrm{Kt} / \mathrm{V} \\
\text { Ort. } \pm \mathrm{SS} \\
1.53 \pm .33\end{array}$ & $\begin{array}{l}<1.2 \\
1.2-1.4 \\
1.4>\end{array}$ & $\begin{array}{c}2 \\
39 \\
73\end{array}$ & $\begin{array}{c}1.8 \\
34.2 \\
64.0\end{array}$ \\
\hline $\begin{array}{l}\text { URR } \\
\text { Ort. } \pm \text { SS } \\
70.32 \pm 7.20\end{array}$ & $\begin{array}{l}>\% 65 \\
\text { Other value }\end{array}$ & $\begin{array}{l}95 \\
19\end{array}$ & $\begin{array}{l}83.3 \\
16.7\end{array}$ \\
\hline Cilt Kuruluğu & $\begin{array}{l}\text { Var } \\
\text { Yok }\end{array}$ & $\begin{array}{l}65 \\
49\end{array}$ & $\begin{array}{l}57.0 \\
43.0\end{array}$ \\
\hline
\end{tabular}

Tablo 3. Ölçeklerden alınan ve alınabilecek puanların dağılımı

\begin{tabular}{|l|c|c|}
\hline & Ort. \pm SS (Min-Maks.) & Ölçekten alınabilecek puanlar \\
\hline & & $1-5$ \\
Kaşıntının süresi & $2.38 \pm 1.40(1-5)$ & $1-5$ \\
Kaşıntının şiddeti & $2.42 \pm 1.35(1-5)$ & $1-5$ \\
Kaşıntının seyri & $2.33 \pm 1.37(1-5)$ & $1-5$ \\
Kaşıntının günlük yaşam aktivitelerine etkisi & $2.66 \pm 1.42(1-5)$ & $1-5$ \\
Vücuttaki dağılımı & $2.63 \pm 1.44(1-5)$ & $5-25$ \\
5-D Kaşıntı Ölçeği Toplam & $12.44 \pm 7.15(5-25)$ & $20-80$ \\
\hline & & $0-100$ \\
Sürekli Anksiyete Ölçeği (SKÖ) & $49.54 \pm 13.03(24-72)$ & \% \\
\hline & & 41.2 \\
Richard-Campbell Uyku Ölçeği (R-CUÖ) & $50.44 \pm 27.71(20-85)$ & 7.0 \\
\hline & $\mathbf{n}$ & 17.5 \\
Çok kötü uyku & 47 & 34.2 \\
Kötü uyku & 8 & 20 \\
İyi uyku & 39 & \\
Çok iyi uyku & & \\
\cline { 2 - 3 }
\end{tabular}


Tablo 4. Kaşıntı Ölçeği Maddelerinin Dağılımı

\begin{tabular}{|c|c|c|c|}
\hline \multicolumn{2}{|l|}{ 5D Kaşıntı ölçeği } & n (114) & $\%$ \\
\hline Kaşıntı Süresi & $\begin{array}{l}16 \text { saatten az } \\
26-12 \text { saat } \\
3 \text { 12-18 saat } \\
4 \text { 18-23 saat } \\
5 \text { Bütün gün }\end{array}$ & $\begin{array}{c}51 \\
11 \\
12 \\
37 \\
3\end{array}$ & $\begin{array}{c}44.7 \\
9.6 \\
10.5 \\
32.5 \\
2.6\end{array}$ \\
\hline Kaşıntı şiddeti & $\begin{array}{l}1 \text { Yok } \\
2 \text { Hafif } \\
3 \text { Orta } \\
4 \text { Ciddi } \\
5 \text { Katlanılmaz }\end{array}$ & $\begin{array}{c}49 \\
11 \\
13 \\
39 \\
2\end{array}$ & $\begin{array}{c}43.0 \\
9.6 \\
11.4 \\
34.2 \\
1.8\end{array}$ \\
\hline Kaşıntı seyri & $\begin{array}{l}\text { 1Tamamen geçmiş } \\
\text { 2Daha iyi ama devam ediyor } \\
\text { 3Biraz iyileşme var ama devam } \\
\text { ediyor } \\
\text { 4Değişmedi hala devam ediyor } \\
5 \text { Daha kötü }\end{array}$ & $\begin{array}{c}50 \\
1 \\
41 \\
\\
19 \\
3\end{array}$ & $\begin{array}{c}43.9 \\
.9 \\
36.0 \\
16.7 \\
2.6\end{array}$ \\
\hline $\begin{array}{l}\text { Günlük yaşam aktivitelerine } \\
\text { etkisi }\end{array}$ & $\begin{array}{l}1 \text { Asla etkilemiyor } \\
\text { 2Nadiren etkiliyor } \\
\text { 3Bazen etkiliyor } \\
\text { 4Genellikle etkiliyor } \\
5 \text { Daima etkiliyor }\end{array}$ & $\begin{array}{c}50 \\
4 \\
19 \\
16 \\
25\end{array}$ & $\begin{array}{c}43.9 \\
3.5 \\
16.7 \\
14.0 \\
21.9\end{array}$ \\
\hline Vücuttaki Dağılım & $\begin{array}{ll}1 & 0-2 \\
2 & 3-5 \\
3 & 6-10 \\
4 & 11-13 \\
5 & 14-16\end{array}$ & $\begin{array}{c}49 \\
13 \\
9 \\
17 \\
26\end{array}$ & $\begin{array}{c}43.0 \\
11.4 \\
7.9 \\
14.9 \\
22.8\end{array}$ \\
\hline
\end{tabular}

Tablo 5. Ölçeklerin korelasyonel ilişki dağılımı

\begin{tabular}{|l|l|c|c|}
\hline & & $\begin{array}{c}\text { Sürekli Anksiyete } \\
\text { Ölçeği }\end{array}$ & $\begin{array}{c}\text { Richard-Campbell Uyku } \\
\text { Ölçeği }\end{array}$ \\
\hline Kaşıntının süresi & & .713 & -.698 \\
& $\mathrm{.r000}$ \\
\hline Kaşıntının şiddeti & $\mathrm{p}$ & $\mathbf{. 0 0 0}$ & -.683 \\
& $\mathrm{r}$ & .701 & $\mathbf{. 0 0 0}$ \\
\hline Kaşıntının seyri & $\mathrm{p}$ & $\mathbf{. 0 0 0}$ & -.526 \\
& $\mathrm{r}$ & .732 & $\mathbf{. 0 0 0}$ \\
\hline Kaşıntının günlük yaşam aktivitelerine etkisi & $\mathrm{p}$ & $\mathbf{. 0 0 0}$ & $\mathbf{- . 6 5 3}$ \\
& $\mathrm{r}$ & .703 & $\mathbf{. 0 0 0}$ \\
\hline Vücuttaki dağ1lımı & $\mathrm{p}$ & $\mathbf{. 0 0 0}$ & $\mathbf{- . 6 9 9}$ \\
& $\mathrm{r}$ & .702 & $\mathbf{. 0 0 0}$ \\
\hline 5-D Kaşıntı Ölçeği Toplam & $\mathrm{p}$ & $\mathbf{. 0 0 0}$ & -.679 \\
& $\mathrm{r}$ & .706 & $\mathbf{0 0 0}$ \\
\hline
\end{tabular}


Tablo 6. Anksiyete ve Uyku Kalitesinin Stepwise multiple linear regresyon modellemesi $(n=114)$

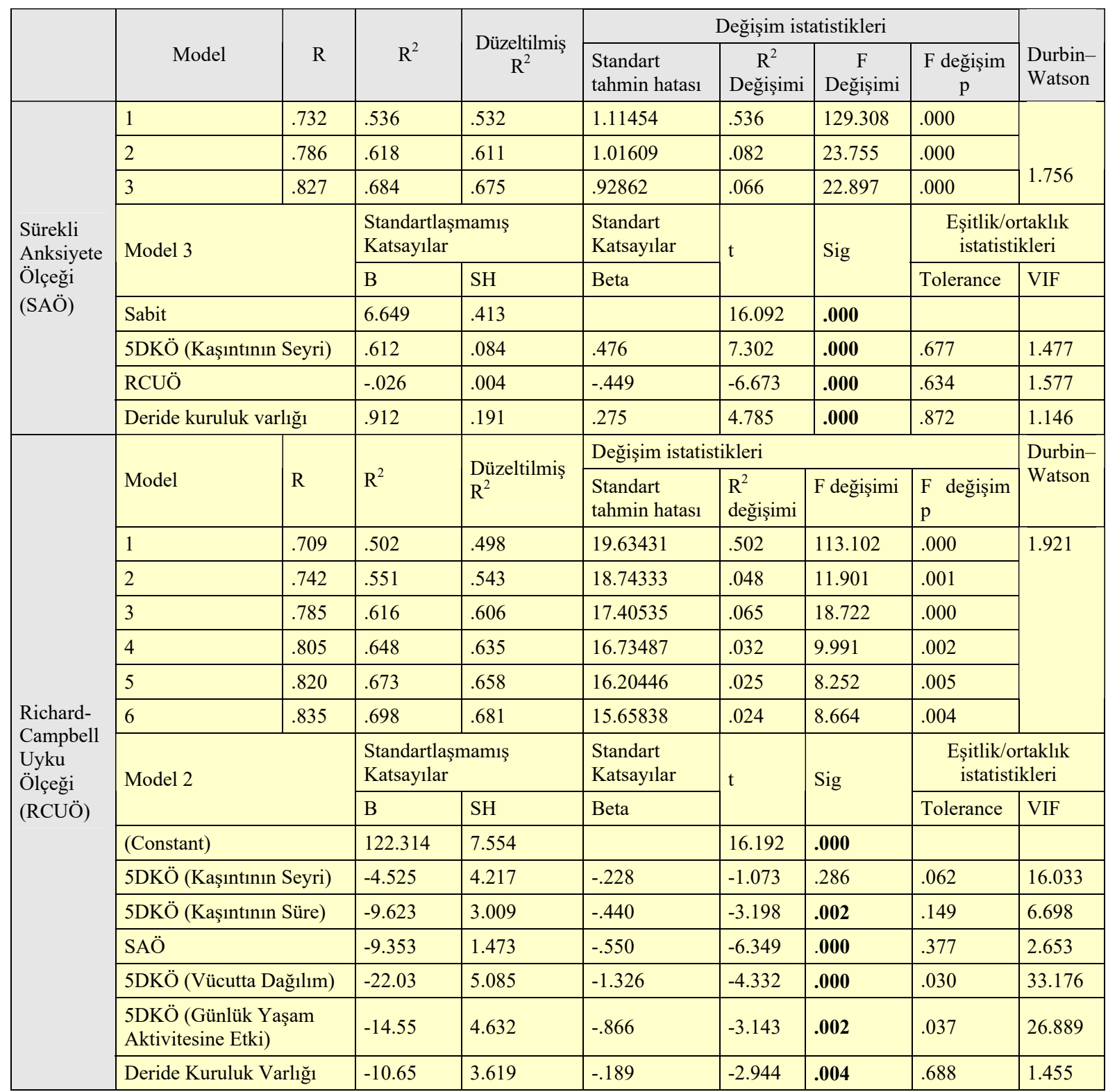

\section{TARTIŞMA}

$\mathrm{Bu}$ çalışmada hemodiyaliz hastalarının yaşadıkları kaşıntı 5 D Kaşıntı Ölçeği kullanılarak çok boyutlu olarak değerlendirildi ve hemodiyaliz hastalarında yaşanan kaşıntı ile uyku ve anksiyete arasındaki ilişki incelendi.

Çalışmada, 5 D Kaşıntı Ölçeğinden alınabilecek toplam maksimum ve minimum puanlar göz önünde bulundurulduğunda hastaların kaşıntıdan önemli derece etkilendikleri anlaşılmaktadır. Hastaların \%32.5'inin kaşıntısının 18 -23 saat sürdüğü, hastaların yarısının ciddi ve orta derecede kaşıntı yaşadığ 1 ve kaşıntının en çok gövde, bacaklar, sırt ve kollarda dağılım gösterdiği belirlendi. Ersoy ve Akyar'ın aynı ölçeği kullanarak hemodiyaliz hastalarında kaşıntıyı değerlendirdiği çalıșmada benzer olarak $5 \mathrm{D}$ ölçeğinin ortalama skoru $13.97 \pm 4.11$ (orta şiddet) olarak belirlenmiştir. Aynı çalışmada kaşıntının günlük süresinin hastaların önemli bir bölümünde (\% 40.3) 612 saat olduğu ve kaşıntının en çok sırt, üst kollar, göğüs ve karında dağılım gösterdiği belirlenmiştir. Hemodiyaliz hastalarında 10 puanlık 
görsel analog skalası kullanılarak yapılan bir çalışmada üremik kaşıntı şiddet skoru $6.7 \pm 2.4$ ve \%51.4' ünün hafif, \% 11.4'ünün orta ve \% 37.7 'sinin şiddetli derece (6) ve diğer bir çalışmada hemodiyaliz hastalarının \% 29'unun orta ve \% 29'unun şiddetli derece kaşıntı yaşadığ 1 bildirilmiştir (28). Yine çalışmalarda hemodiyaliz hastalarında kaşıntının en çok dağılım gösterdiği bölgeler bu çalışmada olduğu gibi gövde, bacaklar, sirt ve kollar olarak gösterilmiştir (1, 23, 29, 30). 5D KÖ maddelerinden bir diğeri de hastaların yaşadıkları kaşıntının günlük yaşamlarını ne kadar etkilediğidir. Hastaların önemli bir bölümü, bu soruya "genellikle" (\%14.1) ve "her zaman" (\%21.9) cevabını vermiştir. Yapılan çalışmalarda hemodiyaliz hastalarında kaşıntının s1k görülen bir durum olduğu, hastaların günlük yaşamlarını ve yaşam kalitelerini etkilediğini göstermektedir $(7,17,31)$.

Çalışmada hemodiyaliz hastalarının uyku kalitesi düşük olarak belirlenirken, hastaların \%41.2'sinin çok kötü uyku kalitesine sahip olduğu belirlendi. Bugüne kadar yapılan çalışmalar, hemodiyaliz hastalarında çeşitli uyku bozukluklarının görüldügünü bildirmiştir $(8,32)$. Literatürde, hemodiyaliz hastalarında düşük uyku kalitesi sıklığının $\% 53.3$ ile $\% 87.0$ arasında değiş̧iklik gösterdiği belirlenmiştir $(8,31,33)$. Yedi ülkede 308 diyaliz ünitesinde 11351 hastada yapılan Diyaliz Sonuçları ve Uygulama Örnekleri Çalışması'nda (DOPPS), yüksek vücut kitle indeksi, ağrı varlığ1, koroner arter hastalığı, konjestif kalp yetmezliği, diyabet, akciğer hastalığı, psikiyatrik bozukluklar, periferik arter hastalı̆̆ gibi diyaliz hastalarının ortak klinik özellikleri zayıf uyku ile anlamlı derecede ilişkili bulunmuştur. Aynı çalışmada düşük uyku puanları ile düşük yaşam kalitesi ve mortalite artış riski arasında ilişki belirlenmiştir (34). Bu bulgular uykunun klinik önemini, tanınmasının ve yönetiminin gerekliliğini göstermektedir.

Çalışmada hastaların orta düzey anksiyete yaşadıkları belirlendi. Anksiyete, son dönem böbrek yetmezliği olan hastalarda yaygın görülen bir psikolojik sorundur. Hemodiyaliz hastalarında anksiyete prevalans1 \% 20.0 ile \% 60.0 arasında değişmektedir $(22,35)$. Bu oranlara bakıldığında hemodiyaliz hastalarının anksiyete açısından değerlendirilmesinin ve psikolojik destek sağlanmasının önemini ortaya koymaktadır.

Çalışmada, hemodiyaliz hastalarında görülen kaşıntının uyku kalitesi ve anksiyete ile ilişkili olduğu belirlendi. Hastaların kaşıntı seyrindeki artış anksiyeteyi artırırken, uyku kalitesini azalttığ1 saptandı. Yine kaşıntının süresi, vücuttaki dağılımı ve günlük yaşam üzerine etkisi arttıkça hastaların uyku kalitesinin azaldığı belirlendi. Literatür hemodiyaliz alan hastalarda uyku kalitesinin büyük ölçüde üremik kaşıntı nedeniyle azaldığını belirtmektedir $(11,21,36$, 37). Bir meta analiz çalışmasında hemodiyaliz tedavisi alan hastalarda üremik kaşıntıya bağlı uyku bozukluğu prevalansının \% 9.0 ile \% 76.0 arasında değiştiği raporlanmıştır (11). Ersoy ve Akyar'ın yaptığı çalışmada, hemodiyaliz hastalarının yarısından fazlasının kaşıntı nedeniyle uykuya dalmada gecikmeler yaşadığı ve bazen kaşıntı nedeniyle gece uykudan uyandıkları belirlenmiştir (23). Benzer olarak diğer çalışmalarda da kaşıntının uykuya dalmada gecikmelere ve gece uykuda kesintilere neden olduğu gösterilmiştir $(36,38)$. Dokuz hemodiyaliz merkezinde 416 hastayla gerçekleştirilen bir çalışmada, şiddetli aşırı uykusuzluğun en önemli belirleyicisi kaşıntı olarak bulunmuştur (36). Ayrıca, üremik kaşıntı yaşayan hastaların üremik kaşıntısı olmayan hastalara kıyasla daha düşük bir uyku kalitesine ve daha ciddi depresyona sahip oldukları belirlenmiştir $(16,37)$. $\mathrm{Bu}$ nedenle, klinik uygulamada hemodiyaliz hastasının kaşıntı ve uyku açısından değerlendirilmesi, hasta sonuçlarının iyileştirilmesinde ve terapötik olarak müdahale edilmesinde önemlidir. Hemodiyaliz hastalarında yaşam kalitesini iyileştirmede özellikle hemşirelik hizmetleri önemlidir. Hemodiyaliz hemşireleri, etkili semptom kontrolü ile hasta şikayetlerini azaltarak, konforlarını ve yaşam kalitelerini artırabilirler. Yapılan çalışmalarda da hemşirelerin uyguladıkları nonfarmakolojik yöntemlerin (masaj, aromaterapi, akupressur, soğuk uygulama, müzik terapi) hemodiyaliz hastalarının yaşadıkları kaşıntıyı azaltıp, yaşam kalitesini, uyku kalitesini, konforlarını arttırdığını gösterilmiştir $(9,10,21$, 
22). Örneğin Karadağ ve ark.'nın çalışmasında kaşıntı şikayeti olan hemodiyaliz hastalarında bebek yağ1 uygulamasının kaşıntı, yaşam kalitesi ve uyku kalitesi üzerinde olumlu etkileri olduğu bulunmuştur (21). Diğer bir çalışmada da akupressur uygulamasının hemodiyaliz hastalar1nın anksiyetesini azalttığı bildirilmiştir (22).

Çalışmada hemodiyaliz hastalarında kaşıntının seyri arttıkça anksiyete puanlarının arttığı görüldü. Bazı çalışmalar da üremik kaşıntının, fiziksel ve zihinsel sinırlamalarla, uykusuzluk ve kronik yorgunluk ile güçlü bir şekilde ilişkili olduğunu; kaşıntılara bağlı lezyonlardan dolayı rahatsızlık, utanç/izolasyon ve ikincil cilt değişikliklerinin öfke, kaygı ve depresyona neden olduğunu göstermektedir $(15,23)$. Çalışmada hemodiyaliz hastalarındaki anksiyetenin kaşıntı dışında diğer belirleyicileri uyku ve kuru cilt olarak belirlendi. Kuru cilt, üremik kaşıntı için potansiyel bir etken faktör olarak gösterilmekte ve kuru cilde sahip olanlarda olmayanlara göre 3,9 kat daha fazla kaşıntıya sahip oldukları bildirilmiştir (13). Kuru cilt ve kaşıntı arasındaki bu ilişki hemodiyaliz hastalarındaki anksiyeteyi açıklayabilir. Çalışmalar uyku bozukluklarının hem fiziksel hem mental yaşam kalitesini etkilediğini göstermektedir $(8,31,32)$. Bu çalışma bulguları ve literatür göz önünde bulundurulduğunda kaşıntının dolaylı etkisinin de yani aracı bir değişken görevi olabileceğini de akla getirmektedir. Başka bir deyişle, kaşıntı uyku kalitesini direk etkilediği gibi uyku kalitesi üzerinden de anksiyeteyi dolaylı etkiliyor olabilir.
Çalışmanın bazı sınırlılıkları bulunmaktadır. Çalışmanın sadece bir ilin iki ilçesindeki diyaliz merkezinde yapılmasından dolayı çalışmanın sonuçları Türkiye'deki tüm hemodiyaliz hastaları için genellenemez. Diğer önemli sinırlılığı ise kaşıntının bu çalışmada aracılık etkisinin değerlendirilmemesidir. Başka çalışmalarda daha büyük örneklem gruplarında kaşıntının aracılık etkisinin incelenmesi önerilmektedir.

\section{SONUÇ}

Kaşınt1, uyku bozukluğu ve anksiyete hemodiyaliz hastalarında sık rastlanan ama genelde hemşire ya da hekim tarafindan görmezden gelinen sorunlardır. Bu çalışmada da hemodiyaliz hastalarının yarısına yakınının orta ve şiddetli derecede kaşıntı yaşadığ 1 ve günlük yaşamlarının önemli derecede etkilendiği belirlendi. Hastaların orta düzey anksiyete yaşadığı ve yarısına yakınının kötü uyku kalitesine sahip olduğu saptandı. Çalışmanın diğer önemli bir sonucu da kaşıntı ile uyku kalitesi ve anksiyete arasındaki ilişkinin varlı̆̆ıdır. $\mathrm{Bu}$ sonuçlara dayanarak hemodiyaliz hastalarında etkin semptom yönetiminin sağlanması için kaşıntı semptomlarının diyaliz hemşiresi tarafından çok boyutlu değerlendirilmesi önerilmektedir. Kaşıntı semptomlarının hemodiyaliz hastalarında çok boyutlu değerlendirilmesi uyku, anksiyete ve yaşam kalitesi üzerindeki etkisinin belirlenmesini sağlayarak hastaların morbiditesini azaltacak ve yaşam kalitesini artıracaktır.

\section{Kaynaklar}

1. Mettang T, Kremer AE. Uremic pruritus. Kidney International. 2015;87(4):685-91.

2. Hashimoto T, Yosipovitch G. Itching as a systemic disease. Journal of Allergy and Clinical Immunology. 2019; 144(2): 375-80.

3. Khan TM, Wu DB-C, Goh B-H, Lee L-H, Alhafez AA, Sulaiman SAS. An observational longitudinal study investigating the effectiveness of $75 \mathrm{mg}$ pregabalin post-hemodialysis among uremic pruritus patients. Scientific Reports. 2016; 6(1): 1-9.

4. Rehman IU, Munib S, Ramadas A, Khan TM. Prevalence of chronic kidney disease-associated pruritus, and association with sleep quality among hemodialysis patients in Pakistan. PloS One. 2018; 13(11): e0207758.

5. Sanai M, Aman S, Nadeem M, Kazmi AH. Dermatologic manifestations in patients of renal disease on hemodialysis. Journal of Pakistan Association of Dermatology. 2016; 20(3): 163-8.

6. Akhyani M, Ganji M-R, Samadi N, Khamesan B, Daneshpazhooh M. Pruritus in hemodialysis patients. BMC Dermatology. 2005; 5(7): 1-6. 
7. Erturk IE, Arican O, Omurlu IK, Sut N. Effect of the pruritus on the quality of life: a preliminary study. Annals of Dermatology. 2012; 24(4): 406-12.

8. Rehman IU, Lai PSM, Lim SK, Lee LH, Khan TM. Sleep disturbance among Malaysian patients with end-stage renal disease with pruritus. BMC Nephrology. 2019; 20(1): 102.

9. Wu C-F, Hsiao Y-C, Ko P-C. The effects of nonpharmacological treatment on uremic pruritus patients: A systematic review. Advances in Nursing. 2015; 2015: 1-9.

10. Lin TC, Lai YH, Guo SE, Liu CF, Tsai JC, Guo HR, et al. Baby oil therapy for uremic pruritus in haemodialysis patients. Journal of Clinical Nursing. 2012; 21(1 - 2): 139-48.

11. Rehman IU, Chohan TA, Bukhsh A, Khan TM. Impact of Pruritus on Sleep Quality of Hemodialysis Patients: A Systematic Review and Meta-Analysis. Medicina. 2019; 55(10): 699.

12. Shirazian S, Aina O, Park Y, Chowdhury N, Leger K, Hou L, et al. Chronic kidney disease-associated pruritus: impact on quality of life and current management challenges. International Journal of Nephrology and Renovascular Disease. 2017; 10: 11-26.

13. Kılıç Akça N, Taşçı S. An important problem among hemodialysis patients: uremic pruritus and Affecting Factors. Turk Nephrol Dial Transplant Journal. 2014; 23(3): 210-6.

14. Lopes GB, Nogueira FCP, de Souza MR, Penalva MA, de Amorim JL, Pisoni RL, et al. Assessment of the psychological burden associated with pruritus in hemodialysis patients using the kidney disease quality of life short form. Quality of Life Research. 2012; 21(4): 603-12.

15. Kılıç AKÇA N, Taşçı S. Kaşıntı Kontrolünde Kullanılan Nonfarmakolojik Yöntemler. TAF Preventive Medicine Bulletin. 2013; 12(3): 359-64.

16. Weiss M, Mettang T, Tschulena U, Passlick-Deetjen J, Weisshaar E. Prevalence of chronic itch and associated factors in hemodialysis patients - Results from a representative cross-sectional study. Acta Derm Venereol. 2015;85(7): 81621.

17. Weiss M, Mettang T, Tschulena U, Weisshaar E. Health-related quality of life in haemodialysis patients suffering from chronic itch: results from GEHIS (German Epidemiology Haemodialysis Itch Study). Quality of Life Research. 2016; 25(12): 3097-106.

18. Ozen N, Cinar FI, Askin D, Mut D. Uremic pruritus and associated factors in hemodialysis patients: A multi-center study. Kidney Research and Clinical Practice. 2018; 37(2): 138-47.

19. Akça NK. Hemodiyaliz Tedavisi Alan Hastalarda Sık Karşılaşılan Cilt Sorunları ve Hemşirelik Bakımı. Nefroloji Hemşireliği Dergisi. 2019; 14(1): 26-32.

20. Elmaati HMBA. Impact of Uremic Pruritus Nursing Management on Itching and Sleep Disturbance among Hemodialysis Patients. World Journal of Nursing Sciences. 2018; 4(3): 149-53.

21. Karadag E, Kilic SP, Karatay G, Metin O. Effect of baby oil on pruritus, sleep quality, and quality of life in hemodialysis patients: Pretest-post - test model with control groups. Japan Journal of Nursing Science. 2014; 11(3): $180-9$.

22. Dehghanmehr S, Mansouri A, Faghihi H, Piri F. The effect of acupressure on the anxiety of patients undergoing hemodialysis-a review. Journal of Pharmaceutical Sciences and Research. 2017; 9(12): 2580-4.

23. Ersoy NA, Akyar İ. Multidimensional pruritus assessment in hemodialysis patients. BMC Nephrology. 2019; 20(42): $1-7$.

24. Daugirdas JT. Second generation logarithmic estimates of single-pool variable volume Kt/V: an analysis of error. Journal of the American Society of Nephrology. 1993; 4(5): 1205-13.

25. Ersoy NA, Akyar İ. Validity and reliability of 5-D itch scale on chronic renal disease patients. Acıbadem Üniversitesi Sağlık Bilimleri Dergisi. 2018; 9(4): 455-61.

26. Özlü ZK, Özer N. Richard-Campbell Uyku Ölçeği Geçerlilik ve Güvenilirlik Çalışması. Journal of Turkish Sleep Medicine. 2015; 2: 29-32.

27. Öner N. Türkiye'de kullanılan psikolojik testler. İstanbul: Boğaziçi Üniversitesi Yayınları. 1997:150-1.

28. Sukul N, Wang M, Bieber B, Li Y, Lopes AA, Speyer E, et al. Sp295 Pruritis in Chronic Kidney Disease Patients: Early Results From Ckdopps. Oxford University Press; 2016.

29. Pisoni RL, Wikström B, Elder SJ, Akizawa T, Asano Y, Keen ML, et al. Pruritus in haemodialysis patients: International results from the Dialysis Outcomes and Practice Patterns Study (DOPPS). Nephrology Dialysis Transplantation. 2006; 21(12): 3495-505.

30. Weisshaar E, Apfelbacher C, Jäger G, Zimmermann E, Bruckner T, Diepgen T, et al. Pruritus as a leading symptom: clinical characteristics and quality of life in German and Ugandan patients. British Journal of Dermatology. 2006; 155(5): 957-64.

31. Edalat-Nejad M, Qlich-Khani M. Quality of life and sleep in hemodialysis patients. Saudi Journal of Kidney Diseases 
and Transplantation. 2013; 24(3): 514-8.

32. Mirghaed MT, Sepehrian R, Rakhshan A, Gorji H. Sleep quality in Iranian hemodialysis patients: A systematic review and meta-analysis. Iranian Journal of Nursing and Midwifery Research. 2019; 24(6): 403-9.

33. Brekke FB, Waldum B, Amro A, Østhus TB, Dammen T, Gudmundsdottir H, et al. Self - perceived quality of sleep and mortality in $\mathrm{N}$ orwegian dialysis patients. Hemodialysis International. 2014; 18(1): 87-94.

34. Elder SJ, Pisoni RL, Akizawa T, Fissell R, Andreucci VE, Fukuhara S, et al. Sleep quality predicts quality of life and mortality risk in haemodialysis patients: results from the Dialysis Outcomes and Practice Patterns Study (DOPPS). Nephrology Dialysis Transplantation. 2008; 23(3): 998-1004.

35. Vasilopoulou C, Bourtsi E, Giaple S, Koutelekos I, Theofilou P, Polikandrioti M. The impact of anxiety and depression on the quality of life of hemodialysis patients. Global Journal of Health Science. 2016; 8(1): 45-55.

36. Soleymanian T, Alidadiani S, Mahdavi A. Pruritus and insomnia in hemodialysis patients; association with SF36 quality of life and clinical outcomes. Journal of Renal Injury Prevention. 2018; 7(4): 253-8.

37. SuSeł J, Batycka-Baran A, Reich A, SzEPIETOWSKI JC. Uraemic pruritus markedly affects the quality of life and depressive symptoms in haemodialysis patients with end-stage renal disease. Acta Dermato-Venereologica. 2014; 94(3): 276-81.

38. Kimata N, Fuller DS, Saito A, Akizawa T, Fukuhara S, Pisoni RL, et al. Pruritus in hemodialysis patients: Results from the $\mathrm{J}$ apanese D ialysis $\mathrm{O}$ utcomes and $\mathrm{P}$ ractice $\mathrm{P}$ atterns $\mathrm{S}$ tudy (JDOPPS). Hemodialysis International. 2014; 18(3): 657-67. 